\title{
Progress on hypoxia-inducible factor-3: Its structure, gene regulation and biological function (Review)
}

\author{
SHENG-LI YANG ${ }^{1}$, CHAO WU $^{1}$, ZHI-FAN XIONG ${ }^{2}$ and XIEFAN FANG ${ }^{3}$ \\ ${ }^{1}$ Department of General Surgery, Liyuan Hospital, Tongji Medical College, Huazhong University of Science and Technology, \\ Wuhan, Hubei 430000; ${ }^{2}$ Department of Medicine and Division of Digestion Disease, Liyuan Hospital, \\ Tongji Medical College, Huazhong University of Science and Technology, Wuhan, Hubei 430077, P.R. China; \\ ${ }^{3}$ Department of Pediatrics, College of Medicine, University of Florida, Gainesville, FL 32610, USA
}

Received July 17, 2014; Accepted March 26, 2015

DOI: $10.3892 / \mathrm{mmr} .2015 .3689$

\begin{abstract}
Hypoxia inducible factors (HIFs) are transcription factors, which are commonly expressed in mammals, including humans. The HIFs consist of hypoxia-regulated $\alpha$ and oxygen-insensitive $\beta$ subunits, and are key regulators of gene expression during hypoxia in normal and solid tumor tissues. Three members of the HIF family, HIF-1 $\alpha, \mathrm{HIF}-2 \alpha$, and HIF-3 $\alpha$, are currently known. HIF-3 $\alpha$ differs from HIF-1 $\alpha$ and HIF- $2 \alpha$ in protein structure and regulation of gene expression. For a long time, HIF-3 $\alpha$ was considered as a negative mediator of HIF-regulated genes. HIF-3 has a transcriptional regulatory function, which negatively affects gene expression by competing with HIF-1 $\alpha$ and HIF- $2 \alpha$ in binding to transcriptional elements in target genes during hypoxia. Previously, certain target genes of HIF-3 $\alpha$ have been identified, confirming the role of HIF- $3 \alpha$ as a transcription factor. In this review, the protein structure, gene regulation and biological function of HIF-3 are discussed based on the literature.
\end{abstract}

\section{Contents}

1. Introduction

2. Structure of human HIF-3

3. Structure of mouse HIF-3 $\alpha$

4. Expression and regulation of HIF- $3 \alpha$

5. Biological functions of HIF-3

6. Association between HIF-3 and diseases

7. Conclusion

Correspondence to: Professor Zhi-Fan Xiong, Department of Medicine and Division of Digestion Disease, Liyuan Hospital, Tongji Medical College, Huazhong University of Science and Technology, 39 Yanhu Road, Wuhan, Hubei 430077, P.R. China

E-mail: xiongzhifan@126.com

Key words: hypoxia-inducible factor-3, transcription factor, hypoxia

\section{Introduction}

Hypoxia-inducible factors (HIFs) are commonly expressed in humans and other mammals as transcriptional factors $(1,2)$. They positively regulate the expression levels of $>100$ target genes, which encode protein products involved in the response to hypoxia (3-5). Tumor hypoxia was first described in the 1950s and currently there is increasing evidence to demonstrate that hypoxia is regulated by HIFs and is a common feature in several types of cancer (6-9). In 1992, Semenza et al (10) identified a nuclear factor, which binds to the 3 '-flanking sequence of the human erythropoietin gene (EPO) and promotes the expression of EPO under anoxic conditions. This factor, termed HIF, is able to increase the number of erythrocytes and increase the efficiency of oxygen transportation (10). At present, three types of HIF have been identified, namely HIF-1 (10), HIF-2 (11) and HIF-3 (12). HIF-3 $\alpha$ is the most recently identified member of the HIF family. Mouse HIF-3 $\alpha$ (mHIF-3 $\alpha$ ) was initially identified by Gu et al in 1998 (12) and human HIF-3 $\alpha$ (hHIF-3 $\alpha$ ) was identified in 2001 (13). HIF-3 $\alpha$ has been investigated to a lesser degree compared with HIF-1 and HIF-2. HIF-1 $\alpha$ and HIF-2 $\alpha$ are often overexpressed in cancer tissue, leading to progression of aggressive tumors, tumor resistance to chemotherapy and radiation, and poor prognosis of the disease (14-17). The role of HIF-3 $\alpha$ in tumors types remains to be elucidated, however, previous studies have indicated that HIF-3 $\alpha$ may suppress the expression of genes, which are typically inducible by HIF- $1 \alpha$ and HIF- $2 \alpha$ in tumor cells $(13,18)$. Therefore, HIF-3 $\alpha$ has transcriptional regulatory functions and is a negative regulator of gene expression during hypoxia $(13,18)$. Furthermore, HIF-3 $\alpha$ is a true transcription factor since it actively stimulates the expression of a number of target genes (19). This review comprehensively discusses the current knowledge of the gene structure, regulation of expression and biological function of HIF-3.

\section{Structure of human HIF-3}

hHIF-3 is a heterodimer, which consists of hypoxia-regulated- $\alpha$ (HIF- $\alpha)$ and oxygen-insensitive $\beta$ subunits, and is a member of the aryl-hydrocarbon receptor nuclear translator (ARNT) family (20). hHIF-3 $\alpha$ is located at chromosome 
19q13.13-13.2 (12), which differs from the locus of HIF-1 $\alpha$ (14q21-24) and HIF-2 $\alpha$ (2p16-21) (10,11). The first full-length hHIF-3 $\alpha$ cDNA, now termed HIF-3 $\alpha 1$, encodes a 668 amino acid protein with a relative molecular mass of $73 \mathrm{kDa}(13)$. The N-terminus of HIF-3 $\alpha$ is a basic-helix-loop-helix (bHLH) region, which is responsible for DNA binding (Fig. 1). Following the bHLH region is a Per/Arnt/Sim (PAS) region, which consists of $\sim 300$ aminophenoal residues. The PAS region contains PAS-A, PAS-B and two replication regions, which form dimmers with the bHLH region of HIF-1 $\beta$ (13). Following the PAS region is an oxygen-dependent degradation (ODD) domain. This oxygen regulatory region is involved in the degradation of HIF-3 $\alpha$ (13). The C-terminus of HIF-3 $\alpha$ is a transactivation domain (TAD). HIF-1 $\alpha$ and HIF-2 $\alpha$ have two TADs, which are located at the $\mathrm{N}$ and $\mathrm{C}$-terminus, however, HIF- $3 \alpha$ has only one TAD at the N-terminus (13). The TAD in HIF-3 $\alpha$ shares $58 \%$ and $52 \%$ identity with the TADs in the $\mathrm{N}$-terminus of HIF-1 $\alpha$ and HIF-2 $\alpha$, respectively (12). Multiple splice variants of hHIF-3 $\alpha$, namely hHIF- $3 \alpha 1-10$, have been reported $(21,22)$. hHIF-3 $\alpha$ has 19 exons spanning $43 \mathrm{~kb}$ in chromosome 19q13.2. Three unique exons, namely exons 1a, $1 \mathrm{~b}$ and $1 \mathrm{c}$, are likely to contain transcription initiation sites for the variants. Exon 2 encodes the bHLH domain and exons 3-9 contain the coding sequence for the PAS domain. HIF-3 $\alpha 2$ consists of 632 amino acids and begins from exon 1a and ends at exon 13a, skipping exons $1 \mathrm{~b}$ and $1 \mathrm{c}$ (22). hHIF-3 $\alpha 3$ begins at exon $1 \mathrm{~b}$ and ends at exon 17, skipping exons $1 \mathrm{a}, 1 \mathrm{c}, 15$ and 16. hHIF-3 $\alpha 3$ has 648 amino acids and contains ODD and LXXLL motifs, however lacks any recognizable DNA-binding sequences, including the bHLH or LZIP domains (22). hHIF-3 $\alpha 4$ encodes a protein of 363 amino acids, which lacks NAD, CAD and ODD domains. Compared with other hHIF-3 $\alpha$ variants, hHIF-3 $\alpha 4$ contains no LXXLL or LZIP motifs (22). hHIF- $3 \alpha 5$ and hHIF-3 $\alpha 6$ start at exon $1 \mathrm{~b}$ and lack exon 3 . hHIF-3 $\alpha 5$ contains a short exon $14 \mathrm{c}$ and ends at exon 15 , and it encodes a protein containing partial PASa, PASb and PAC domains. hHIF-3 $\alpha 6$, similar to hHIF-3 $\alpha 4$, contains intron 7 and ends at intron 8 , and it contains only a partial PASb domain at the C-terminus (22). Similar to the HIF- $\alpha$ subunit, HIF-1 $\beta$ contains bHLH, PAS and TAD domains (Fig. 1). However, HIF-1 $\beta$ lacks the ODD domain, therefore, it is constitutively expressed in all tissues under aerobic conditions (23-25).

\section{Structure of mouse HIF-3 $\alpha$}

The open reading frame of $\mathrm{mHIF}-3 \alpha$ spans $1.98 \mathrm{~kb}$, containing 15 exons, and encodes a protein of 662 amino acids (12). mHIF- $3 \alpha$ has also been reported to produce alternatively spliced variants, the mouse inhibitory PAS domain protein (IPAS) $(26,27)$ and neonatal and embryonic PAS protein (NEPAS) (28). Mouse IPAS is a hypoxia-inducible short splice variant of mHIF-3 $\alpha$ and shares three exons (2, 4 and 5) with HIF-3. Mouse IPAS lacks NTAD, CTAD and ODD domains (26) and is known to bind to HIF-1 $\alpha$, however not HIF- $\beta$ (27). Similar to IPAS, NEPAS mRNA is derived from HIF- $3 \alpha$ and contains the first exon (1a) of IPAS followed by the 2 nd to 15 th exon of HIF-3 $\alpha$ (28). NEPAS encodes a polypeptide of 664 amino acids, containing the NTAD and ODD domains (28). Unlike IPAS, NEPAS is able to dimerize with HIF- $\beta$ (28).

\section{Expression and regulation of HIF-3 $\alpha$}

The expression profiles of HIF-1 $\alpha$ and HIF-2 $\alpha$ have been well documented (29). However, the expression profiles of HIF-3 $\alpha$ variants are only recently investigated. HIF- $3 \alpha$ is expressed in human kidney (13) and lung epithelial cells (30). Northern blot analysis demonstrated that the mRNA expression of hHIF-3 $\alpha$ is high in the heart, placenta and skeletal muscle, however, is low in the lung, liver and kidney (22). Immunofluorescence analysis demonstrated that HIF-3 $\alpha$ is present in the cytoplasm and nucleus under normoxic conditions, and that exposure to hypoxia increases the nuclear fraction of HIF-3 $\alpha$ (31). mHIF- $3 \alpha$ is expressed in the adult thymus, lung, heart and kidney (12). In mice, IPAS is predominantly expressed in corneal epithelium and Purkinje cells of the cerebellum (26). NEPAS is expressed almost exclusively in the late embryonic and early postnatal stages, with the expression predominantly located in the lungs and heart (28). By contrast, IPAS is not detected during embryonic development (28).

The expression of HIF-3 is predominantly regulated at the transcriptional and post-transcriptional levels, which are described in the following sections.

Regulation of HIF-3 $\alpha$ expression at the transcriptional level Hypoxia. Hypoxia increases the mRNA expression levels of HIF-3 $\alpha$. Heidbreder et al (32) revealed that the mRNA expression levels of HIF-3 $\alpha$ were significantly increased in the lung and other organs following a 2-h hypoxic exposure in rats. This was confirmed by two other studies $(33,34)$. Zhang et al $(35)$ demonstrated that hypoxia increases the mRNA and protein expression levels of HIF-3 $\alpha$ in zebrafish.

$H I F-1$ and HIF-2. HIF-3 $\alpha$ is a target gene of HIF-1 and modulates the expression of hypoxic genes (31). Tanaka et al (31) revealed that siRNA-mediated knockdown of HIF-1 $\alpha$ in human renal cell carcinoma notably dampened the 2, 2'-dipyridy-stimulated induction of HIF-3 $\alpha$ protein. In addition, immunohistochemical analysis revealed co-localization of HIF- $1 \alpha$ and HIF-3 $\alpha$ in cells (31). Pasanen et al (21) demonstrated that HIF-3 $\alpha 2$ and HIF- $3 \alpha 4$ are inducible during hypoxia and the inductions require HIF-1 $\alpha$. A similar previous study revealed that HIF-1 $\alpha$ binds to the hypoxia response element (HRE) in the IPAS promoter and induces the expression of IPAS (36). However, the stabilized form of HIF-1 $\alpha$ does not affect the mRNA expression levels of HIF-3 $\alpha$ in zebrafish embryos (35) and 3T3-L1 cells (37). This contradictory result may be due to the different cell lines or animal models used in the experiments. In addition to HIF-1 $\alpha$, Hatanaka et al (37) observed that the promoter activity of HIF-3 $\alpha$ is specifically activated by HIF- $2 \alpha$. HIF- $2 \alpha$ specifically binds to the sequence between -251 and -228 in the mHIF-3 $\alpha$ promoter, which is essential in response to the activation of HIF-2 $\alpha$ (37). In human umbilical venous endothelial cells, the expression of HIF-3 $\alpha$ is driven by HIF-1 and HIF-2 (18).

2-Deoxy-D-glucose (2-DG) and insulin. 2-DG and insulin are able to cause a widespread increase in the mRNA expression levels of HIF-3 $\alpha$. Following treatment with 2-DG in rats, the expression of HIF-3 $\alpha$ was markedly increased in the lung, heart and kidney by 9.6-, 9.0- and 4.1-fold, respectively (38). Following treatment with insulin, the mRNA expression of HIF- $3 \alpha$ is significantly increased in every major tissue and 


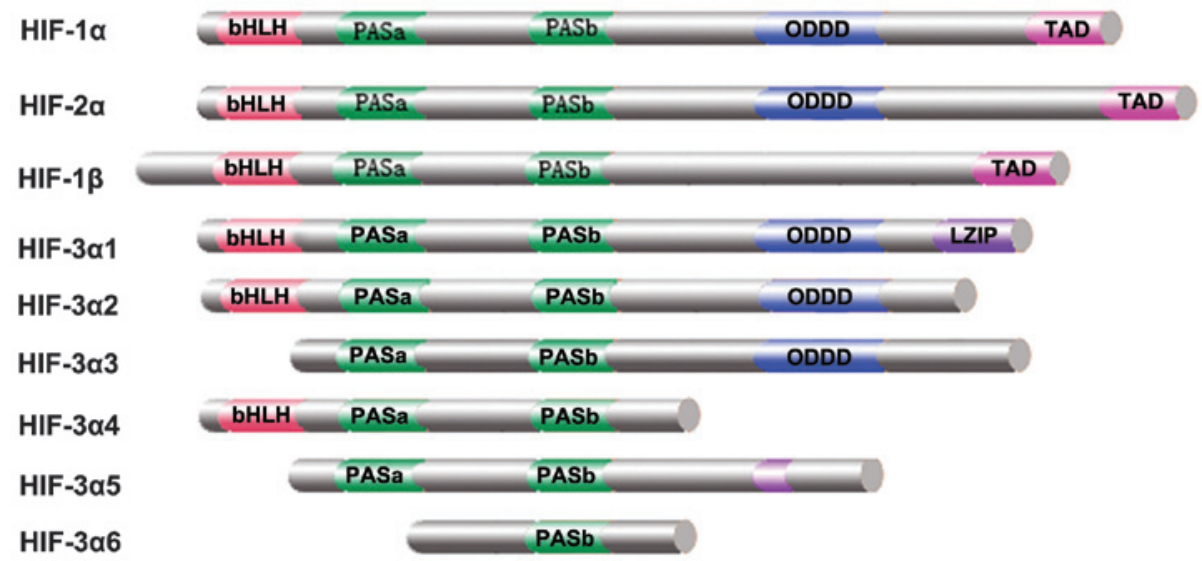

Figure 1. Schematic overview of the domain structures of HIF- $\alpha$ isoforms. The majority of the isoforms contain the bHLH and PAS domains, which are required for dimerization and DNA binding. HIF-1 $\alpha$, HIF-2 $\alpha$, HIF-3 $\alpha 1$, HIF-3 22 and HIF-3 33 also contain an ODDD, which contains the conserved proline(s). Only HIF-3 $\alpha 1$ contains a LZIP domain. HIF, hypoxia-inducible factor; ODDD, oxygen-dependent degradation domain; bHLH, basic helix-loop-helix; LZIP, leucine zipper.

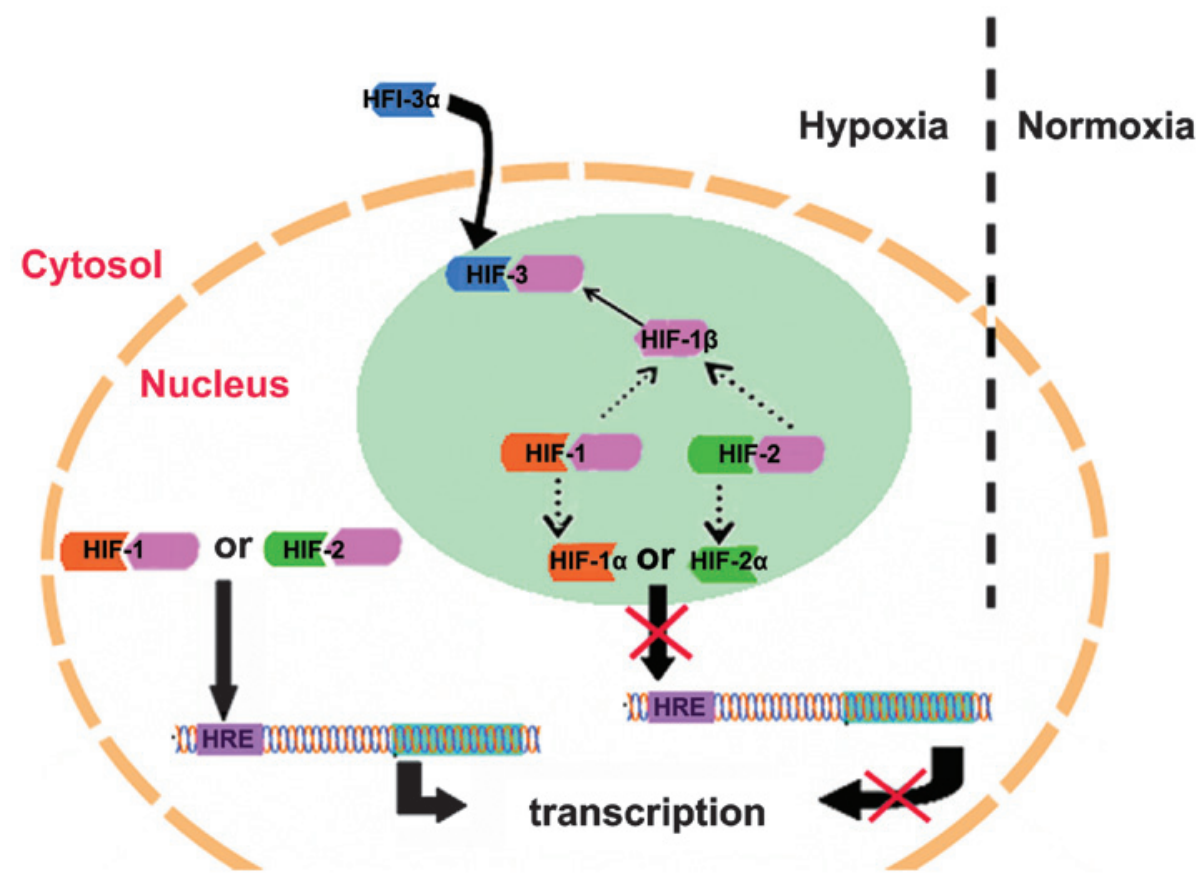

Figure 2. Mechanism of HIF-3 $\alpha$ suppression of HIF-1 and HIF-2-mediated gene expression. HIF-3 $\alpha$ competes with HIF-1 $\alpha$ and HIF-2 $\alpha$ in binding to the HIF-1 $\beta$ subunits, reduces the expression levels of HIF-1 and HIF-2, therefore repressing the upregulation of target gene expression stimulated by HIF-1 and HIF-2. HIF, hypoxia-inducible factor; HRE, hypoxia response element.

organ; however, the induction is not as high as that following treatment with 2-DG (38).

Regulation of HIF-3 $\alpha$ expression at the post-transcriptional level

Hypoxia. The mRNA expression of HIF-3 $\alpha$ is increased significantly in A549 cells exposed to a low oxygen environment for $2 \mathrm{~h}$ (30). On one hand, hypoxia markedly increases the protein synthesis of HIF-3 $\alpha$ within 30 min exposure. Conversely, hypoxia reduces the degradation of HIF-3 $\alpha$ protein and therefore, relatively increases its protein level (30).

Von Hippel-Lindau (VHL). VHL is a tumor suppressor gene involved in VHL syndrome and renal cell carcinoma (39-41). Maynard et al (22) demonstrated that hHIF-3 $\alpha 1-3$ splice variants share a common ODD domain, which can be degraded by the pVHL ubiquitin-proteasome under normal oxygen partial pressure. The ability of VHL to degrade HIF3 $\alpha$ is dependent on the proline 490 residue on HIF3 $\alpha$ and this is increased in the presence of prolyl hydroxylase (PHD).

PHD. PHD is a cellular sensor for low-oxygen. Under normal oxygen partial pressure and in the presence of $\mathrm{Fe}^{2+}$ and acetone dicarboxylic acid, PHD catalyzes the hydroxylation of key amino acid residues in the HIF- $\alpha$ ODD domain $(42,43)$. This is followed by VHL binding to HIF- $\alpha$ and inducing degradation via the ubiquitin-proteasome pathway $(44,45)$. Chen et al (46) demonstrated that the in vivo protein level of HIF-3 $\alpha$ under hypoxic conditions is negatively correlated with the protein expression levels of PHD2 and PHD3, whereas the 
content of HIF- $3 \alpha$ mRNA is positively correlated with the mRNA expression levels of PHD2 and PHD3. It is possible that PHD increases the protein degradation of HIF-3 $\alpha$, which is followed by negative feedback upregulation of the mRNA expression of HIF-3 $\alpha$ in order to compensate for the loss of the HIF-3 $\alpha$ protein.

Deferoxamine (DFX) and $\mathrm{CoCl}_{2}$. DFX and $\mathrm{CoCl}_{2}$ increase the protein expression levels of HIF-3 $\alpha$ (30). DFX binds to iron and interrupts the hydroxylation of proline in the ODD domain of HIFs, by preventing the binding of the VHL ubiquitin-proteasome complex to HIF-3 $\alpha$ and eventually leads to the accumulation of intracellular HIF-3 $\alpha$ protein $(30,47,48)$. Similarly, $\mathrm{CoCl}_{2}$ reduces the degradation of HIF-3 $\alpha$ by occupying its binding site for the VHL ubiquitin-proteasome complex, resulting in an increased protein expression of HIF-3 $\alpha(30,49,50)$.

\section{Biological functions of HIF-3}

Following protein stabilization during hypoxia, HIF-1 $\alpha$ and HIF- $2 \alpha$ dimerize with HIF- $\beta$, bind to co-activators, including p300, and interact with the HRE of target genes $(51,52)$. Compared with HIF- $1 \alpha$ and HIF-2 $\alpha$, HIF- $3 \alpha$ has dual functions: Inhibition of the activities of HIF- $1 \alpha$ and HIF-2 $\alpha$, and regulation of its own target genes (19).

hHIF-3 $\alpha 1$ has been demonstrated to suppress HIF-1 and HIF-2-mediated gene expression (13). Hara et al (13) transfected expression vectors of HIF-1 $\alpha$, HIF- $2 \alpha$ or HIF-3 $\alpha$ into COS-7 cells and demonstrated that HIF- $1 \alpha$ and HIF-2 $\alpha$ promote the transcription of HREs, whereas HIF-3 $\alpha 1$ inhibits HRE transcription. A previous study revealed that HIF-3 $\alpha 1$ inhibits the expression levels of HIF- $1 \alpha$ and HIF- $2 \alpha$ (13). It is suggested that HIF-3 $\alpha$ competes with HIF- $1 \alpha$ and HIF- $2 \alpha$ in binding to HIF-1 $\beta$ subunits, reduces the levels of HIF-1 and HIF-2, and ultimately inhibits the upregulation of the target genes of HIF-1 and HIF-2 (Fig. 2) (13). Additionally, HIF-3a lacks a transcriptional activation domain, and its bHLH and PAS domains suppress the expression of target genes, which are typically inducible by HIF-1 $\alpha$ and HIF- $2 \alpha$ (13). Splice variant IPAS dimerizes with HIF-1 $\alpha$ protein and disrupts the interaction between HIF-1 $\alpha$ and the HRE of its target genes (36). Makino et al (36) demonstrated that there is a negative feedback mechanism between HIF- $1 \alpha$ and IPAS. At first, HIF-1 $\alpha$ binds to the HRE in the IPAS promoter and induces the expression of IPAS (36). Increased levels of IPAS dimerize with HIF-1 $\alpha$ protein and inhibits further induction of IPAS (36). In hepatoma cells, ectopic expression of IPAS decreases the expression of vascular endothelial growth factor (VEGF), resulting in reduced tumor growth and decreased tumor vascular density in vivo (27). The splice variant, HIF-3 $\alpha 4$, is different from IPAS in terms of its structure and gene regulation. For example, IPAS only binds to HIF-1 $\alpha$, whereas HIF-3 $\alpha 4$ binds to HIF-1 $\alpha$ and ARNT (53). The HIF-3 $\alpha 4 /$ HIF- $\beta$ complex binds to HREs, which inhibits the binding of the HIF- $1 \alpha /$ HIF- $\beta$ complex to the HRE (53). The HIF-3 $\alpha 4 /$ HIF- $\beta$ complex is not transcriptionally active, however, it significantly reduces HIF-1-mediated promoter activation by acting as a dominant negative regulator of HIF-1 (53). Similar to IPAS, ectopic expression of HIF-3a4 inhibits the endogenous expression of hypoxia-responsive genes, including glucose transporter-1 (GLUT-1), and knocking down the endogenous expression of HIF-3 $\alpha 4$ using siRNA increases the transcription of HIF target genes (53). Besides HIF- $1 \alpha$ and HIF- $\beta$, HIF- $3 \alpha 4$ also binds to HIF- $2 \alpha$ and inhibits HIF-2-mediated transactivation of HRE-driven genes (54). In addition, overexpression of HIF-3 $\alpha 4$ in clear-cell renal cell carcinoma (CCRCC) cells reduces endogenous expression of HIF-2 target genes and inhibits the growth of CCRCC xenografts in severe combined immunodeficiency mice (54). These findings suggest that HIF-3 $\alpha 4$ has a dominant negative role in suppressing CCRCC growth and has a potential therapeutic role in the treatment of CCRCC (54). A previous study revealed that overexpression of HIF-3 $\alpha 4$ impairs angiogenesis, proliferation, and metabolism/oxidation of hypervascular meningioma (55). Therefore, HIF-3 44 is a potential molecular target for the treatment of meningioma (55).

It is reported that siRNA-mediated knockdown of HIF-3 $\alpha$ induces the expression of certain HIF- $1 \alpha$-mediated genes and decreases the expression of ANGPTL4 in response to hypoxia (31). This indicates that HIF-3 $\alpha$ also possesses transcriptional activity. All the hHIF- $3 \alpha$ variants were demonstrated to be able to bind to HIF- $\beta$ and overexpression of certain HIF-3 $\alpha$ variants, together with HIF- $\beta$, induces the mRNA expression levels of several HIF-1 and HIF-2 target genes, including EPO $(56,57)$, ANGPTL4 $(58,59)$ and GLUT1 $(60,61)$. However, the overexpression of HIF-3 $\alpha$ variants reveals no significant stimulation of the expression of HRE-driven reporter genes (62), suggesting that the target genes induced by HIF-3 $\alpha$ variants may contain specific response elements, which are not canonical HREs $(31,62)$.

Zhang et al (19) revealed that HIF-3 $\alpha$ exhibits significant transactivation activity in zebrafish. The authors performed transcriptomic analyses and identified a large number of HIF-3 target genes, which can be divided to three categories: i) Genes that are upregulated by HIF-3a only (e.g. sqrdl, mclb and zp3v2); ii) genes that are regulated by HIF-1 $\alpha$ and HIF-3 $\alpha$ with similar potencies (e.g. redd1 and mlp3c); and iii) genes that are regulated by HIF-1a and HIF-3a, however, with different potencies (e.g. igfbpla) (19). Notably, the authors demonstrated that the transcriptional activity is conserved across species and hHIF-3a-9 isoforms stimulate similar target genes in different human cell types, including LC3C, REDD1 and SQRDL cells (19). These findings suggest that HIF-3 is an oxygen-dependent transcription factor, which activates a distinctive set of genes in response to hypoxia.

\section{Association between HIF-3 and diseases}

Tissue hypoxia is a pathological feature of several human diseases, including myocardial infarction, stroke and kidney disease (63-65). The expression of HIF-3 $\alpha$ is often altered in these diseases and may contribute to their development $(32,66)$. It has been reported that the mRNA expression of HIF-3a is increased as an early response to acute hypoxia and acute myocardial ischemia in humans and experimental animal models $(32,66)$. Zolk et al (67) demonstrated that the mRNA expression level of HIF- $1 \alpha$ is $51 \%$ lower in cardiac tissue from a patient with heart failure compared with that of a healthy control. By contrast, the expression of HIF-2 $\alpha$ remains unchanged and the mRNA expression of HIF-3 $\alpha$ is 
$72 \%$ higher in cardiac tissue from a patient with heart failure compared with healthy control (67).

In addition, HIF-3 exerts abnormal expression patterns in liver and kidney disease (68). Hypoxia-associated molecules are upregulated during cystic alteration into a heterogeneous appearance (68). In polycystic liver, VEGF is markedly and widely expressed in the cytoplasm of hepatocytes (68), and the expression of HIF-3 $\alpha$, however not HIF- $1 \alpha$, is observed in a few nuclei of hepatocytes adjacent to the biliary areas (68). By contrast, VEGF, HIF- $1 \alpha$ and HIF- $3 \alpha$ proteins are not present in the cytoplasm or nuclei of hepatocytes in the control livers (68). Therefore, it is hypothesized that the presence of HIF- $3 \alpha$ in periportal hepatocytes is associated with the induction of VEGF (68). Fang et al (69) demonstrated that HIF-3 $\alpha$ is one of the mediators, which contribute to the development of primary spontaneous pneumothorax.

\section{Conclusion}

Based on the current knowledge, HIF-3 $\alpha$ has a dual role in response to hypoxia: It suppresses HIF-1 and HIF-2-mediated gene expression and induces the expression of their own target genes by binding to the HRE or specific response elements of varying lengths, which are distinct from the canonical HRE. The function of HIF-3 $\alpha$ remains to be fully elucidated, however, it is an important factor for the fine-tuning of the hypoxic response in humans in physiological and pathological conditions $(62,70)$. A previous study identified certain target genes of HIF- $3 \alpha$ and confirmed its role as a transcription factor (19). Understanding the biological roles of HIF-3 $\alpha$ is important for identifying a potential therapeutic target for the treatment of diseases.

\section{Acknowledgements}

The authors would like to thank Dr Shu-Cai Yang from the Chinese University of Hong Kong for providing the figures.

\section{References}

1. Rankin EB, Giaccia AJ and Schipani E: A central role for hypoxic signaling in cartilage, bone and hematopoiesis. Curr Osteoporos Rep 9: 46-52, 2011.

2. Loenarz C, Coleman ML, Boleininger A, et al: The hypoxia-inducible transcription factor pathway regulates oxygen sensing in the simplest animal, Trichoplax adhaerens. EMBO Rep 12: 63-70, 2011 .

3. Semenza GL: Hypoxia-inducible factors in physiology and medicine. Cell 148: 399-408, 2012.

4. Greer SN, Metcalf JL, Wang Y and Ohh M: The updated biology of hypoxia-inducible factor. EMBO J 31: 2448-2460, 2012.

5. Goda N and Kanai M: Hypoxia-inducible factors and their roles in energy metabolism. Int J Hematol 95: 457-463, 2012.

6. Ye J, Wu D, Wu P, Chen $\mathrm{Z}$ and Huang J: The cancer stem cell niche: Cross talk between cancer stem cells and their microenvironment. Tumour Biol 35: 3945-3951, 2014

7. Yang SL, Liu LP, Jiang JX, Xiong ZF, He QJ and Wu C: The correlation of expression levels of HIF-1 $\alpha$ and HIF- $2 \alpha$ in hepatocellular carcinoma with capsular invasion, portal vein tumor thrombi and patients' clinical outcome. Jpn J Clin Oncol 44: 159-167, 2014.

8. Cao S, Yang S, Wu C, Wang Y, Jiang J and Lu Z: Protein expression of hypoxia-inducible factor-1 alpha and hepatocellular carcinoma: A systematic review with meta-analysis. Clin Res Hepatol Gastroenterol 38: 598-603, 2014.

9. Tsai YP and Wu KJ: Hypoxia-regulated target genes implicated in tumor metastasis. J Biomed Sci 19: 102, 2012.
10. Semenza GL and Wang GL: A nuclear factor induced by hypoxia via de novo protein synthesis binds to the human erythropoietin gene enhancer at a site required for transcriptional activation. Mol Cell Biol 12: 5447-5454, 1992.

11. Tian H, McKnight SL and Russell DW: Endothelial PAS domain protein 1 (EPAS1), a transcription factor selectively expressed in endothelial cells. Genes Dev 11: 72-82, 1997.

12. Gu YZ, Moran SM, Hogenesch JB, Wartman L and Bradfield CA: Molecular characterization and chromosomal localization of a third alpha-class hypoxia inducible factor subunit, HIF3alpha. Gene Expr 7: 205-213, 1998.

13. Hara S, Hamada J, KobayashiC, Kondo Y and Imura N: Expression and characterization of hypoxia-inducible factor (HIF)-3alpha in human kidney: Suppression of HIF-mediated gene expression by HIF-3alpha. Biochem Biophys Res Commun 287: 808-813, 2001.

14. Ku JH, Park YH, Myung JK, Moon KC, Kwak C and Kim HH: Expression of hypoxia inducible factor- $1 \alpha$ and $2 \alpha$ in conventional renal cell carcinoma with or without sarcomatoid differentiation. Urol Oncol 29: 731-737, 2011.

15. Luan Y, Gao C, Miao Y, Li Y, Wang Z and Qiu X: Clinicopathological and prognostic significance of HIF-1a and HIF-2 $\alpha$ expression in small cell lung cancer. Pathol Res Pract 209: 184-189, 2013.

16. Kroeger N, Seligson DB, Signoretti S, et al: Poor prognosis and advanced clinicopathological features of clear cell renal cell carcinoma (ccRCC) are associated with cytoplasmic subcellular localisation of Hypoxia inducible factor- $2 \alpha$. Eur J Cancer 50: 1531-1540, 2014.

17. Gong L, Zhang W, Zhou J, et al: Prognostic value of HIFs expression in head and neck cancer: A systematic review. PLoS One 8: e75094, 2013.

18. Augstein A, Poitz DM, Braun-Dullaeus RC, Strasser RH and Schmeisser A: Cell-specific and hypoxia-dependent regulation of human HIF-3 $\alpha$ : Inhibition of the expression of HIF target genes in vascular cells. Cell Mol Life Sci 68: 2627-2642, 2011.

19. Zhang P, Yao Q, Lu L, Li Y, Chen PJ and Duan C: Hypoxia-inducible factor 3 is an oxygen-dependent transcription activator and regulates a distinct transcriptional response to hypoxia. Cell Reports 6: 1110-1121, 2014.

20. Semenza GL: Hypoxia-inducible factor 1: Master regulator of $\mathrm{O}_{2}$ homeostasis. Curr Opin Genet Dev 8: 588-594, 1998.

21. Pasanen A, Heikkila M, Rautavuoma K, Hirsila M, Kivirikko KI and Myllyharju J: Hypoxia-inducible factor (HIF)-3alpha is subject to extensive alternative splicing in human tissues and cancer cells and is regulated by HIF-1 but not HIF-2. Int J Biochem Cell Biol 42: 1189-1200, 2010.

22. Maynard MA, Qi H, Chung J, et al: Multiple splice variants of the human HIF-3 alpha locus are targets of the von Hippel-Lindau E3 ubiquitin ligase complex. J Biol Chem 278: 11032-11040, 2003.

23. Huang LE, Arany Z, Livingston DM and Bunn HF: Activation of hypoxia-inducible transcription factor depends primarily upon redox-sensitive stabilization of its alpha subunit. J Biol Chem 271: 32253-32259, 1996.

24. Whitelaw ML, Gustafsson JA and Poellinger L: Identification of transactivation and repression functions of the dioxin receptor and its basic helix-loop-helix/PAS partner factor Arnt: inducible versus constitutive modes of regulation. Mol Cell Biol 14: 8343-8355, 1994.

25. Reyes H, Reisz-Porszasz S and Hankinson O: Identification of the Ah receptor nuclear translocator protein (Arnt) as a component of the DNA binding form of the Ah receptor. Science 256: 1193-1195, 1992.

26. Makino Y, Kanopka A, Wilson WJ, Tanaka $\mathrm{H}$ and Poellinger L: Inhibitory PAS domain protein (IPAS) is a hypoxia-inducible splicing variant of the hypoxia-inducible factor-3alpha locus. J Biol Chem 277: 32405-32408, 2002.

27. Makino Y, Cao R, Svensson K, et al: Inhibitory PAS domain protein is a negative regulator of hypoxia-inducible gene expression. Nature 414: 550-554, 2001.

28. Yamashita $\mathrm{T}$, Ohneda $\mathrm{O}$, Nagano $\mathrm{M}$, et al: Abnormal heart development and lung remodeling in mice lacking the hypoxia-inducible factor-related basic helix-loop-helix PAS protein NEPAS. Mol Cell Biol 28: 1285-1297, 2008.

29. Majmundar AJ, Wong WJ and Simon MC: Hypoxia-inducible factors and the response to hypoxic stress. Mol Cell 40: 294-309, 2010.

30. Li QF, Wang XR, Yang YW and Lin H: Hypoxia upregulates hypoxia inducible factor (HIF)-3alpha expression in lung epithelial cells: Characterization and comparison with HIF-1alpha. Cell Res 16: 548-558, 2006. 
31. Tanaka T, Wiesener M, Bernhardt W, Eckardt KU and Warnecke C: The human HIF (hypoxia-inducible factor)-3alpha gene is a HIF-1 target gene and may modulate hypoxic gene induction. Biochem J 424: 143-151, 2009.

32. Heidbreder M, Frohlich F, Johren O, Dendorfer A, Qadri F and Dominiak P: Hypoxia rapidly activates HIF-3alpha mRNA expression. FASEB J 17: 1541-1543, 2003.

33. Rajatapiti P, de Rooij JD, Beurskens LW, et al: Effect of oxygen on the expression of hypoxia-inducible factors in human fetal lung explants. Neonatology 97: 346-354, 2010.

34. Li QF and Dai AG: Differential expression of three hypoxia-inducible factor-alpha subunits in pulmonary arteries of rat with hypoxia-induced hypertension. Acta Biochim Biophys Sin (Shanghai) 37: 665-672, 2005.

35. Zhang P, Lu L, Yao Q, et al: Molecular, functional and gene expression analysis of zebrafish hypoxia-inducible factor-3alpha. Am J Physiol Regul Integr Comp Physiol 303: R1165-R1174, 2012.

36. Makino Y, Uenishi R, Okamoto K, et al: Transcriptional up-regulation of inhibitory PAS domain protein gene expression by hypoxia-inducible factor 1 (HIF-1): a negative feedback regulatory circuit in HIF-1-mediated signaling in hypoxic cells. J Biol Chem 282: 14073-14082, 2007.

37. Hatanaka M, Shimba S, Sakaue M, et al: Hypoxia-inducible factor-3alpha functions as an accelerator of 3T3-L1 adipose differentiation. Biol Pharm Bull 32: 1166-1172, 2009.

38. Heidbreder M, Qadri F, Johren O, et al: Non-hypoxic induction of HIF-3alpha by 2-deoxy-D-glucose and insulin. Biochem Biophys Res Commun 352: 437-443, 2007.

39. Choueiri TK, Fay AP, Gagnon R, et al: The role of aberrant VHL/HIF pathway elements in predicting clinical outcome to pazopanib therapy in patients with metastatic clear-cell renal cell carcinoma. Clin Cancer Res 19: 5218-5226, 2013.

40. Kennedy BK: A new connection between VHL and cancer threads through progerin. Cell Cycle 12: 2721-2722, 2013.

41. Bausch B, Jilg C, Glasker S, et al: Renal cancer in von Hippel-Lindau disease and related syndromes. Nat Rev Nephrol 9: 529-538, 2013

42. Pientka FK, Hu J, Schindler SG, et al: Oxygen sensing by the prolyl-4-hydroxylase PHD2 within the nuclear compartment and the influence of compartmentalisation on HIF-1 signalling. J Cell Sci 125: 5168-5176, 2012.

43. Niecknig H, Tug S, Reyes BD, Kirsch M, Fandrey J and Berchner-Pfannschmidt U: Role of reactive oxygen species in the regulation of HIF-1 by prolyl hydroxylase 2 under mild hypoxia. Free Radic Res 46: 705-717, 2012.

44. Groulx I and Lee S: Oxygen-dependent ubiquitination and degradation of hypoxia-inducible factor requires nuclear-cytoplasmic trafficking of the von Hippel-Lindau tumor suppressor protein. Mol Cell Biol 22: 5319-5336, 2002.

45. Ivan M, Kondo K, Yang H, et al: HIFalpha targeted for VHL-mediated destruction by proline hydroxylation: Implications for O2 sensing. Science 292: 464-468, 2001.

46. Chen YR, Dai AG, Hu RC and Jiang YL: Differential and reciprocal regulation between hypoxia-inducible factor-alpha subunits and their prolyl hydroxylases in pulmonary arteries of rat with hypoxia-induced hypertension. Acta Biochim Biophys Sin (Shanghai) 38: 423-434, 2006

47. Harvey AJ, Kind KL and Thompson JG: Regulation of gene expression in bovine blastocysts in response to oxygen and the iron chelator desferrioxamine. Biol Reprod 77: 93-101, 2007.

48. Woo KJ, Lee TJ, Park JW and Kwon TK: Desferrioxamine, an iron chelator, enhances HIF-1alpha accumulation via cyclooxygenase-2 signaling pathway. Biochem Biophys Res Commun 343: 8-14, 2006.

49. Triantafyllou A, Liakos P, Tsakalof A, Georgatsou E, Simos G and Bonanou S: Cobalt induces hypoxia-inducible factor-1alpha (HIF-1alpha) in HeLa cells by an iron-independent, but ROSPI-3K- and MAPK-dependent mechanism. Free Radic Res 40: 847-856, 2006

50. Yuan Y, Hilliard G, Ferguson T and Millhorn DE: Cobalt inhibits the interaction between hypoxia-inducible factor-alpha and von Hippel-Lindau protein by direct binding to hypoxia-inducible factor-alpha. J Biol Chem 278: 15911-15916, 2003.
51. Wu D, Zhang R, Zhao R, Chen G, Cai Y and Jin J: A novel function of novobiocin: Disrupting the interaction of HIF 1alpha and p300/CBP through direct binding to the HIF1alpha C-terminal activation domain. PLoS One 8: e62014, 2013.

52. Mendonca DB, Mendonca G, Aragao FJ and Cooper LF NF-kappaB suppresses HIF-1alpha response by competing for P300 binding. Biochem Biophys Res Commun 404: 997-1003, 2011.

53. Maynard MA, Evans AJ, Hosomi T, Hara S, Jewett MA and Ohh M: Human HIF-3alpha4 is a dominant-negative regulator of HIF-1 and is down-regulated in renal cell carcinoma. FASEB J 19: 1396-1406, 2005.

54. Maynard MA, Evans AJ, Shi W, Kim WY, Liu FF and Ohh M: Dominant-negative HIF-3 alpha 4 suppresses VHL-null renal cell carcinoma progression. Cell Cycle 6: 2810-2816, 2007.

55. Ando H, Natsume A, Iwami K, et al: A hypoxia-inducible factor (HIF)-3alpha splicing variant, HIF-3alpha4 impairs angiogenesis in hypervascular malignant meningiomas with epigenetically silenced HIF-3alpha4. Biochem Biophys Res Commun 433 139-144, 2013.

56. Shah YM and Xie L: Hypoxia-inducible factors link iron homeostasis and erythropoiesis. Gastroenterology 146: 630-642, 2014.

57. Haase VH: Regulation of erythropoiesis by hypoxia-inducible factors. Blood Rev 27: 41-53, 2013.

58. Li H, Ge C, Zhao F, et al: Hypoxia-inducible factor 1 alpha-activated angiopoietin-like protein 4 contributes to tumor metastasis via vascular cell adhesion molecule-1/integrin beta1 signaling in human hepatocellular carcinoma. Hepatology 54 910-919, 2011.

59. Imamura T, Kikuchi H, Herraiz MT, et al: HIF-1alpha and HIF-2alpha have divergent roles in colon cancer. Int J Cancer 124: 763-771, 2009.

60. Marin-Hernandez A, Gallardo-Perez JC, Ralph SJ, Rodriguez-Enriquez S and Moreno-Sanchez R: HIF-1alpha modulates energy metabolism in cancer cells by inducing over-expression of specific glycolytic isoforms. Mini Rev Med Chem 9: 1084-1101, 2009.

61. Airley RE and Mobasheri A: Hypoxic regulation of glucose transport, anaerobic metabolism and angiogenesis in cancer: Novel pathways and targets for anticancer therapeutics. Chemotherapy 53: 233-256, 2007.

62. Heikkila M, Pasanen A, Kivirikko KI and Myllyharju J: Roles of the human hypoxia-inducible factor (HIF)-3alpha variants in the hypoxia response. Cell Mol Life Sci 68: 3885-3901, 2011.

63. Deshmukh AB, Patel JK, Prajapati AR and Shah S: Perspective in chronic kidney disease: targeting hypoxia-inducible factor (HIF) as potential therapeutic approach. Ren Fail 34: 521-532, 2012.

64. Kones R: Oxygen therapy for acute myocardial infarction-then and now. A century of uncertainty. Am J Med 124: 1000-1005, 2011.

65. Shi H: Hypoxia inducible factor 1 as a therapeutic target in ischemic stroke. Curr Med Chem 16: 4593-4600, 2009.

66. Lee SH, Wolf PL, Escudero R, Deutsch R, Jamieson SW and Thistlethwaite PA: Early expression of angiogenesis factors in acute myocardial ischemia and infarction. N Engl J Med 342: 626-633, 2000

67. Zolk O, Solbach TF, Eschenhagen T, Weidemann A and Fromm MF: Activation of negative regulators of the hypoxia-inducible factor (HIF) pathway in human end-stage heart failure. Biochem Biophys Res Commun 376: 315-320, 2008.

68. Yoshida T, Kuwahara M, Maita $K$ and Harada $T$ : Immunohistochemical study on hypoxia in spontaneous polycystic liver and kidney disease in rats. Exp Toxicol Pathol 53: $123-128,2001$.

69. Fang HY, Lin CY, Chow KC, Huang HC and Ko WJ: Microarray detection of gene overexpression in primary spontaneous pneumothorax. Exp Lung Res 36: 323-330, 2010.

70. Drevytska T, Gavenauskas B, Drozdovska S, Nosar V, Dosenko V and Mankovska I: HIF-3alpha mRNA expression changes in different tissues and their role in adaptation to intermittent hypoxia and physical exercise. Pathophysiology 19: 205-214, 2012. 